\title{
EDUKASI PENGELOLAAN KAKI DIABETIK TERHADAP KEMAMPUAN KLIEN MENGIDENTIFIKASI RISIKO ULKUS DIABETIK
}

\author{
Ummu Habibah¹, Busjra M. Nur², Eka Yudha Chrisanto ${ }^{3}$ \\ ${ }^{1}$ Akademi Keperawatan Bhakti Husada Cikarang, Banten. Email: hb_ummu@yahoo.com \\ 2Fakultas IImu Keperawatan, Universitas Muhammadiyah Jakarta \\ 3Akademi Keperawatan Malahayati Bandar Lampung. Email: yudhachrisanto88@gmail.com

\section{ABSTRACT: EDUCATION FOR SECONDARY PREVENTION OF FOOT ULCERS IN PEOPLE WITH DIABETES}

Background: More than 378 million people worldwide suffered DM and nationally there was an increase prevalence of diabetes mellitus with age $\geq 15$ years from $1.1 \%$ to $2.1 \%$.

Purpose: This study was to determined the effect of education for secondary prevention of foot ulcers in people with diabetes.

Methods: A quasi-experimental research (Quasy-experiment) was non Equivalent Control Group Design with pretest-posttest form. The number of sample was 38 respondents (19 treatment group, 38 control group). The results used dependent test was $p$-value $=0.000$ ( $p$-value $<0.05$ ).

Results: The multiple logistic regression, the variables of age, education, history of diabetes and a history of ulcer longer have value $p$-value $>0.05$. The variables of age, education, history of diabetes and a history of ulcer previously not confounding the client's ability level in the treatment group and the control group.

Suggestion: This research useful for the hospital management in the prevention of diabetic foot ulcers which could be early recognized.

\section{Keyword : Education, Diabetes, foot ulcers}

Pendahuluan: Lebih dari 378 juta orang di seluruh dunia mengalami DM dan secara nasional terjadi peningkatan prevalensi kasus DM dengan usia $\geq 15$ tahun dari $1,1 \%$ menjadi $2,1 \%$.

Tujuan: Penelitian ini untuk mengetahui pengaruh edukasi pengelolaan kaki diabetik terhadap kemampuan klien dalam mengidentifikasi risiko ulkus diabetik.

Metode: Penelitian ini dilaksanakan di Rumah Sakit Umum Daerah Kota Bekasi pada bulan Mei-Juni 2016. Metoda penelitian eksperimen semu (quasy-experiment) yaitu non Equivalent Control Group Design dengan bentuk pretest-postest dengan tehnik pengambilan sampel menggunakan purposive sampling. Jumlah sampel sebanyak 38 responden (19 kelompok perlakuan, 38 kelompok kontrol). Prosedur pengumpulan data dilakukan empat hari, hari pertama dan kedua dilakukan edukasi, sebelum dilakukan edukasi pada hari pertama dilakukan pre-test. Hari ketiga latihan mandiri dan post-test dilakukan pada hari keempat.

Hasil : Pada uji t-test dependent didapatkan $p$-value $=0,000$ ( $p$-value $<0,05$ ). Hasil uji regresi linier ganda, variabel usia, pendidikan, riwayat lama DM dan riwayat ulkus mempunyai nilai $p$-value $>0,05$. Variabel usia, pendidikan, riwayat lama DM dan riwayat ulkus bukanlah confounding bagi tingkat kemampuan klien pada kelompok perlakuan dan kelompok kontrol.

Saran: Penelitian ini bermanfaat bagi pelayanan rumah sakit dalam program pencegahan ulkus kaki diabetik yang dapat dikenal oleh klien sejak dini.

\section{Kata kunci : Edukasi, Kaki Diabetik, Ulkus Kaki Diabetik}

\section{PENDAHULUAN}

Saat ini DM sebagai penyakit kronis telah menjadi penyakit epidemik, ini dibuktikan dalam 10 tahun terakhir terjadi peningkatan kasus dua sampai tiga kali lipat, hal ini disebabkan oleh bertambahnya usia, berat badan, dan gaya hidup. Menurut International of Diabetic Ferderation tingkat prevalensi global penderita DM pada tahun 2014 sebesar 8,3\% dari keseluruhan penduduk di dunia dan mengalami peningkatan menjadi 387 juta kasus (Ogurtsova, da Rocha, Fernandes, Huang, Linnenkamp, Guariguata, Cho, \& Makaroff, 2017). Klien DM, dibandingkan dengan klien non DM mempunyai kecenderungan dua kali lebih mudah mengalami trombosis serebral, dua puluh kali berpotensi terjadi buta, dua kali berpotensi terjadi penyakit jantung koroner, tujuh belas kali berpotensi terjadi gagal ginjal kronik, dan lima 


\section{EDUKASI PENGELOLAAN KAKI DIABETIK TERHADAP KEMAMPUAN KLIEN MENGIDENTIFIKASI RISIKO ULKUS DIABETIK}

puluh kali berpotensi menderita ulkus diabetic (Sari \& Hisyam, 2014). Komplikasi menahun DM di Indonesia terdiri atas neuropati $60 \%$, penyakit jantung koroner 20,5\%, ulkus diabetik $15 \%$, retinopati $10 \%$, dan nefropati $7,1 \%$ (Waspadji, \& Bachtiar, 2006).

Komplikasi jangka panjang dari DM salah satunya adalah ulkus diabetik yaitu $15 \%$ dan $85 \%$ merupakan penyebab terjadinya amputasi pada klien DM (Barrett, Clayton, Concannon, Akolkar, Cooper, Erlich \& Plagnol, 2009). Walaupun angka kejadian ulkus diabetik kecil yaitu $15 \%$ pada kaki, akan tetapi mempunyai dampak besar (Hanlon \& Heitzman, 2010). Dewasa ini, persoalan kaki diabetik masih kurang dapat perhatian dan kurang dimengerti sehingga masih muncul pemahaman dan tindakan yang kurang tepat pada pengelolaan kaki diabetik sebagai upaya pencegahan. Permasalahan ini banyak dialami oleh klien dengan DM dan bila dibiarkan terus menerus maka akan merugikan klien di masa yang akan dating (Yunus, 2015). Sampai saat ini di Indonesia kaki diabetik masih merupakan masalah yang rumit dan tidak terkelola dengan maksimal, karena sedikit sekali orang yang berminat menggeluti kaki diabetik (Yunir, Waspadji, \& Rahajeng, 2009). Kaki diabetik yang tidak terkelola dengan baik dan benar akan mudah mengalami masalah yang lebih lanjut yaitu luka dan bahkan dapat menjadi ulkus gangrene (Utami, 2017; Rosikhoh, 2016).

Ada 4 pilar utama dalam penatalaksanaan DM tipe 2, yaitu edukasi, terapi gizi medis, latihan jasmani, dan intervensi farmakologis (Perkumpulan Endokrinologi Indonesia, 2011). Edukasi diabetik adalah pendidikan dan pelatihan mengenai pengetahuan dan ketrampilan bagi klien DM yang bertujuan menunjang perubahan perilaku untuk meningkatkan pemahaman klien akan penyakitnya, yang diperlukan untuk mencapai keadaan yang optimal, dan penyesuaian keadaan psikologik serta kualitas hidup yang lebih baik. Edukasi merupakan bagian integral dari asuhan perawatan klien DM (Eliana \& Yarsi, 2015; Darliana, 2011). Pentingnya edukasi pada klien DM dibuktikan oleh beberapa penelitian sebelumnya tentang Pengaruh Diabetes Self Manajemen Education terhadap ulkus diabetik dengan hasil bahwa ada pengaruh Diabetes Self Managemen Education terhadap risiko terjadinya ulkus diabetik pada klien rawat jalan dengan DM
Tipe 2 di RSUD dr. Soebandi Jember (Wantiyah \& Susanto, 2014). Penelitian yang senada juga dilakukan oleh Rad University tahun 2015 dalam penelitian Diabetes; Research Data from Radboud University Update Understanding of Diabetes (Patient education for preventing diabetic foot ulceration) pada klien dengan risiko tinggi ulkus kaki selama satu tahun didapatkan adanya penurunan insiden ulkus diabetik dan amputasi dengan edukasi secara kelompok selama 1 jam. Studi pendahuluan di RSUD Kota Bekasi dari bulan September 2015-Februari 2016 di tiga ruang rawat inap Penyakit Dalam terdapat kasus DM sebanyak 354 kasus dari 1.835 kasus keseluruhan, ini menunjukkan bahwa dalam kurun waktu 6 bulan terdapat $19 \%$ kasus DM yang dirawat di RSUD Kota Bekasi. Kasus DM diruangan masingmasing tersebut menempati urutan pertama atau kedua dibandingkan dengan kasus yang lain.

Edukasi pada klien DM untuk mengurangi dan menghindari komplikasi DM khususnya ulkus diabetik harus terus ditingkatkan oleh para tenaga kesehatan, mengingat bahwa komplikasi ini akan terus mengintai para klien dengan DM (Widayati, 2015). Pihak utama yang sangat berperan dalam hal ini adalah diri sendiri, oleh karena itu penting dilakukan peningkatan yang terus menerus pada pengetahuan dan pemahaman klien DM tentang pencegahan ulkus diabetik dengan edukasi (Rahmaningsih, Hidayat, \& Novita, 2016). Edukasi pencegahan ulkus diabetik harus lebih komprehensif dengan pengetahuan tentang pengelolaan kaki diabetik, bahwa terjadinya ulkus diabetik tidak semata-mata karena DM yang dideritanya saja namun juga beberapa faktor lain diantaranya adalah pengetahuan tentang perawatan kaki dan tanda-tanda munculnya risiko ulkus (Kristiani, Sumangkut \& Limpeleh, 2015).

\section{METODE PENELITIAN}

Jenis penelitian ini adalah kuantitatif dengan metode penelitian quasi eksperimen yaitu untuk mengetahui pengaruh edukasi pengelolaan kaki diabetik terhadap kemampuan klien mengidentifikasi risiko ulkus diabetik di Rumah Sakit Umum Daerah Kota Bekasi dengan pre test dan post test pada kelompok kontrol dan perlakuan. Populasi dalam penelitian ini adalah seluruh klien DM tipe II yang dirawat di tiga ruang rawat inap Penyakit Dalam Rumah Sakit Umum

Ummu Habibah' Akademi Keperawatan Bhakti Husada Cikarang, Banten. Email: hb_ummu@yahoo.com

Busjra M. Nur ${ }^{2}$ Fakultas llmu Keperawatan, Universitas Muhammadiyah Jakarta

Eka Yudha Chrisanto ${ }^{3}$ Akademi Keperawatan Malahayati Bandar Lampung.

Email: yudhachrisanto88@gmail.com 


\section{EDUKASI PENGELOLAAN KAKI DIABETIK TERHADAP KEMAMPUAN KLIEN MENGIDENTIFIKASI RISIKO ULKUS DIABETIK}

Kota Bekasi dengan tehnik pengambilan sampel menggunakan purposive sampling. Penelitian ini dilaksanakan di Rumah Sakit Umum Daerah Kota Bekasi pada bulan Mei-Juni 2016. Instrumen yang digunakan dalam penelitian ini adalah format pemeriksaan kaki dan kuesioner yang terdiri dari kuesioner perawatan kaki dan pencegahan trauma pada kaki dengan merujuk pada Foot Risk Assement Form Guide (Guide, 2009). dan Nottingham Assessment of Functional Foot care (Senussi, Lincoln \& Jeffcoate, 2011). Prosedur pengumpulan data dilakukan selama 4 hari, hari pertama awal pertemuan responden diberikan format untuk mengidentifikasi risiko ulkus dengan pemeriksaan fisik dan kuesioner perawatan kaki, setelah mengisi format tersebut responden mulai diberikan edukasi. Edukasi ini bertahap sampai pada hari kedua responden pada kelompok perlakuan diberikan edukasi dan latihan mengidentifikasi risiko ulkus pada kelompok perlakuan sedangkan pada kelompok kontrol hanya diberikan modul saja tanpa edukasi. Hari ketiga responden diberi kesempatan untuk latihan mandiri dalam melatih kemampuan mengidentifikasi risiko ulkus. Pada hari keempat peneliti memberikan kembali format identifikasi risiko ulkus kepada responden.

\section{HASIL}

Tabel 1. Distribusi Usia, Pendidikan, Riwayat Lama DM dan Riwayat Ulkus pada Klien DM Tipe II ( $\mathrm{N}=38)$.

\begin{tabular}{llcccc}
\hline Kategorik & & \multicolumn{2}{c}{$\begin{array}{c}\text { Kelp perlakuan } \\
(\mathbf{n}=19)\end{array}$} & \multicolumn{2}{c}{$\begin{array}{c}\text { Kelp kontrol } \\
(\mathbf{n}=19)\end{array}$} \\
& & $\mathbf{f}$ & $\%$ & $\mathbf{f}$ & $\%$ \\
\hline Usia & 40-49 tahun & 6 & 31.6 & 10 & 52.6 \\
& 50-60 tahun & 13 & 68.4 & 9 & 47.4 \\
Pendidikan & SD & 5 & 26.3 & 1 & 5.3 \\
& SMP & 2 & 10.5 & 7 & 36.8 \\
& SMA & 9 & 47.4 & 9 & 47.4 \\
& PT & 3 & 15.8 & 2 & 10.5 \\
Lama dg DM & $<10$ thn & 16 & 84.2 & 9 & 47.4 \\
& $\geq 10$ thn & 3 & 15.8 & 10 & 52.6 \\
\multirow{2}{*}{ Riwayat ulkus } & Pernah & 2 & 10.5 & 8 & 42.1 \\
& Tdk pernah & 17 & 89.5 & 11 & 57.9 \\
& & & & & \\
\hline
\end{tabular}

Tabel 1 menunjukan jumlah persentase terbesar usia terdapat pada kelompok perlakuan dengan usia 50-60 tahun sebanyak 13 orang (68.4\%) sedangkan pada kelompok kontrol tidak ada perbedaan yang signifikan antara usiausia dibawah 50 tahun dengan yang di atas 50 tahun. Bila dilihat dari keseluruhan jumlah responden (total dari kelompok perlakuan dan kontrol) maka jumlah responden yang berusia dibawah 50 tahun dan yang di atas 50 tahun hampir sama banyak yaitu $58 \%$ dan $42 \%$. Untuk persentase pendidikan, jumlah persentase terbesar terdapat pada kelompok perlakuan kontrol dengan pendidikan SMA sebanyak masing-masing orang (47.4\%), hal ini memungkinkan pemahaman proses pembelajaran pada kedua kelompok akan dapat berjalan optimal baik dengan edukasi maupun tanpa edukasi dikarenakan pada kelompok kontrol tetap masih ada proses pembelajaran dengan pemberian modul tentang pengelolaan kaki diabetik dimana di dalamnya terdapat latihan penentuan kriteria risiko ulkus. Jumlah responden dengan lama responden mengalami DM dengan persentase terbesar pada kelompok perlakuan yaitu $<10$ tahun yang berjumlah total 26 orang $(84,2 \%)$. Data tersebut dapat mengindikasikan bahwa jumlah responden yang tidak mempunyai riwayat ulkus akan juga lebih dominan

Ummu Habibah' Akademi Keperawatan Bhakti Husada Cikarang, Banten. Email: hb_ummu@yahoo.com

Busjra M. Nur ${ }^{2}$ Fakultas llmu Keperawatan, Universitas Muhammadiyah jakarta

Eka Yudha Chrisanto ${ }^{3}$ Akademi Keperawatan Malahayati Bandar Lampung.

Email: yudhachrisanto88@gmail.com 


\section{EDUKASI PENGELOLAAN KAKI DIABETIK TERHADAP KEMAMPUAN KLIEN MENGIDENTIFIKASI RISIKO ULKUS DIABETIK}

dikarenakan tingkat kejadian ulkus akan semakin tinggi pada riwayat $\mathrm{DM} \geq 10$ tahun. Riwayat ulkus dengan persentase terbesar pada kelompok perlakuan adalah tidak pernah sebanyak 17 orang (89,5\%). Data ini berkorelasi dengan jumlah responden dengan lama DM $<10$ tahun seperti pemaparan sebelumnya.

Tabel 2. Perbedaan kemampuan klien diabetik sebelum dan sesudah edukasi antara kelompok kontrol dan kelompok perlakuan $(\mathrm{N}=38)$.

\begin{tabular}{llclllll}
\hline Kelompok & Pre-post & Mean & SD & SE & p-value 1 & p-value 2 & N \\
\hline \multirow{2}{*}{ Perlakuan } & Pre test & 30.42 & 8.432 & 1.935 & & & \\
& Post test & 83.28 & 9.085 & 2.084 & 0.00 & & \\
& & & & & & 0.00 & 38 \\
\multirow{2}{*}{ Kontrol } & Pre test & 29.96 & 11.852 & 2.71 & & & \\
& Post test & 47.47 & 13.832 & 3.40 & 0.00 & \\
\hline
\end{tabular}

Pada tabel 2 menunjukan terdapat perbedaan signifikan kemampuan antara kelompok perlakuan dan kontrol dimana $p$-value 0.00 ( $p$-valu $e<0.05$ ). Maka dapat dikatakan bahwa adanya proses pembelajaran di kedua kelompok. Pada kelompok perlakuan dilakukan edukasi pada hari pertama dan kedua dan mendapatkan pula modul pembelajaran. Sedangkan pada kelompok kontrol meskipun tidak mendapat edukasi namun mendapat modul pembelajaran sehingga tetap ada proses pembelajaran.

Tabel 3. Hasil seleksi bivariat regresi linier ganda klien DM dengan kemampuan mengidentifikasi risiko ulkus $(\mathrm{N}=38)$.

\begin{tabular}{cc}
\hline Variabel & p-value \\
\hline Umur & 0.764 \\
Pendidikan & 0.720 \\
Lama DM & 0.523 \\
Riwayat ulkus & 0.325 \\
\hline
\end{tabular}

Tabel 3 menunjukan tidak ada variabel confounding dengan $p$-value $<0.25$ yang bermakna bahwa variabel usia, pendidikan, riwayat lama DM dan riwayat ulkus tidak menjadi confounding yang dapat mempengaruhi kemampuan klien pada kelompok perlakuan dan kontrol maka uji analisa multivariat tidak dilanjutkan.

\section{PEMBAHASAN}

Hasil penelitian ini menunjukkan bahwa kemampuan antara kelompok dengan rata-rata skor setelah edukasi lebih tinggi pada kelompok perlakuan dibandingkan dengan kelompok kontrol, hal ini memperlihatkan bahwa edukasi dengan proses diskusi, tanya jawab dan melakukan demontrasi-redemonstrasi tetap lebih optimal dalam meningkatkan kemampuan klien dalam mengidentifikasi risiko ulkus dibandingkan dengan klien belajar secara mandiri pada kelompok kontrol dimana kelompok ini hanya mendapatkan modul pembelajaran tanpa edukasi. Perlakuan dan kontrol mempunyai perbedaan yang signifikan dengan didapatkan $p$-value 0.000 . Mean kelompok

Ummu Habibah' Akademi Keperawatan Bhakti Husada Cikarang, Banten. Email: hb_ummu@yahoo.com

Busjra M. Nur ${ }^{2}$ Fakultas llmu Keperawatan, Universitas Muhammadiyah Jakarta

Eka Yudha Chrisanto ${ }^{3}$ Akademi Keperawatan Malahayati Bandar Lampung.

Email: yudhachrisanto88@gmail.com 


\section{EDUKASI PENGELOLAAN KAKI DIABETIK TERHADAP KEMAMPUAN KLIEN MENGIDENTIFIKASI RISIKO ULKUS DIABETIK}

perlakuan mempunyai nilai yang lebih tinggi dari kelompok kontrol yaitu 57.03 dan 37.74 .

Penelitian Windasari (2015) mempunyai hasil yang mirip dengan hasil penelitian di atas yaitu kedua kelompok diperoleh nilai $p$-value 0,000 ( $p$ value $<0,05$ ) yang menunjukkan bahwa terdapat perbedaan yang bermakna kepatuhan merawat kaki sebelum dansesudah diberikan pendidikan kesehatan pada kelompok perlakuan dan kelompok kontrol. Penelitian oleh Rad University tahun 2015 dalam penelitian Diabetes; Research Data from Radboud University Update Understanding of Diabetes (Patient education for preventing diabetic foot ulceration) pada klien dengan risiko tinggi ulkus kaki selama 1 tahun dengan hasil bahwa didapatkan adanya penurunan insiden ulkus diabetik dan amputasi dengan edukasi secara kelompok selama 1 jam. Meskipun kelompok kontrol mempunyai perbedaan yang signifikan antara pre test dan post test, tetap saja kelompok perlakuan mempunyai keunggulan tersendiri dengan adanya perbedaan yang signifikan, kemampuan antara kedua kelompok tersebut. Hal ini mengandung makna bahwa edukasi dengan diskusi, tanya jawab dan demonstrasi memegang peranan penting sekali dalam meningkatkan kemampuan klien mengidentifikasi masalah. Penelitian Windasari (2015) juga didapatkan bahwa kelompok yang mendapatkan edukasi melalui metode ceramah dan demonstrasi lebih patuh dalam merawat kaki dibanding kelompok yang tidak mendapatkan edukasi. Hal ini membuktikan bahwa melalui edukasi, terjadi perubahan perilaku kepatuhan responden dalam merawat kaki (Rantung, Yetti \& Herawati, 2015). Hal ini sejalan dengan peletakan edukasi sebagai pencegahan primer pada klien DM karena dengan edukasi maka klien akan memahami dan terus akan dapat memandirikan pengelolaan dirinya khususnya dalam menghindari terjadinya ulkus dengan kemampuan mengidentifikasi risiko ulkus (Hasibuan, 2018; Pelawati, 2017).

Variabel usia, pendidikan, riwayat lama DM dan riwayat ulkus tidak dapat menjadi confounding diantara peningkatan kemampuan kelompok perlakuan dan kelompok kontrol. Oleh karena itu dapat dikatakan bahwa peningkatan pengetahuan, pemahaman dan ketrampilan pada klien DM khususnya DM tipe II dapat dilakukan pada tiap level dan tingkatan, tentu dengan memperhatikan metode, waktu dan bentuk modul pembelajaran.

\section{SIMPULAN}

Ada perbedaan kemampuan yang signifikan pada kelompok kontrol dan perlakuan sebelum dan sesudah edukasi serta ada perbedaan kemampuan yang signifikan antara kelompok kontrol dan perlakuan. Namun tidak ada satupun variabel usia, pendidikan, riwayat lama DM dan riwayat ulkus yang mempengaruhi kemampuan klien dalam mengidentikasi risiko ulkus.

\section{SARAN}

Bagi keperawatan diharapkan meningkatkan pelayanan edukasi dalam melakukan asuhan keperawatan pada klien DM tipe II khususnya dalam mengidentifikasi risiko masalah ulkus yang dapat menjadi salah satu program pencegahan ulkus kaki diabetik yang dapat dikenal oleh klien sejak dini. Bagi peneliti selanjutnya hendaknya melakukan penelitian lanjutan terkait edukasi untuk memandirikan klien dalam pencegahan sekunder. Pencegahan sekunder menjadi juga sangat penting karena ulkus pada klien DM mengalami proses penyembuhan yang lama dan berisiko pada kecacatan bahkan kematian. Dalam penelitian selanjutnya tentang DM sebaiknya tetap memperhatikan kondisi psikologis klien DM karena kondisi penyakit yang kronis dan sering bolak balik ke rumah sakit membuat rasa optimis klien semakin berkurang.

\section{DAFTAR PUSTAKA}

Barrett, J. C., Clayton, D. G., Concannon, P., Akolkar, B., Cooper, J. D., Erlich, H. A., \& Plagnol, V. (2009). Genome-wide association study and meta-analysis find that over 40 loci affect risk of type 1 diabetes. Nature genetics, 41(6), 703.

Darliana, D. (2011). Manajemen asuhan keperawatan pada pasien diabetes melitus. Idea Nursing Journal, 2(2), 132-136.

Eliana, F., SpPD, K. E. M. D., \& Yarsi, B. P. D. F. (2015). Penatalaksanaan DM Sesuai Konsensus Perkeni 2015. PB. Perkeni. Jakarta.

Ummu Habibah' Akademi Keperawatan Bhakti Husada Cikarang, Banten. Email: hb_ummu@yahoo.com

Busjra M. Nur ${ }^{2}$ Fakultas llmu Keperawatan, Universitas Muhammadiyah Jakarta

Eka Yudha Chrisanto ${ }^{3}$ Akademi Keperawatan Malahayati Bandar Lampung.

Email: yudhachrisanto88@gmail.com 
EDUKASI PENGELOLAAN KAKI DIABETIK TERHADAP KEMAMPUAN KLIEN MENGIDENTIFIKASI RISIKO ULKUS DIABETIK

Guide, F. R. A. F. (2009). Diabetes Care Program of Nova Scotia.

Hanlon, M., \& Heitzman, S. (2010). A review of tax research. Journal of accounting and Economics, 50(2-3), 127-178.

Hasibuan, P. N. (2018). Pengaruh Pendampingan; Konsultasi Gizi terhadap Pengendalian Kadar Gula Darah pada Lansia penderita Diabetes Melitus di Puskesmas Padang Bulan Medan.

Kristiani, A. L., Sumangkut, R. M., \& Limpeleh, $H$. P. (2015). Hubungan Ankle Brachial Index dengan keparahan ulkus pada penderita kaki diabetik. Jurnal Biomedik, 7(3).

Ogurtsova, K., da Rocha Fernandes, J. D., Huang, Y., Linnenkamp, U., Guariguata, L., Cho, N. H., \& Makaroff, L. E. (2017). IDF Diabetes Atlas: Global estimates for the prevalence of diabetes for 2015 and 2040. Diabetes research and clinical practice, 128, 40-50.

Pelawati, R. (2017). Pengaruh Pendidikan Kesehatan Terhadap Tingkat Pengetahuan tentang Penyakit Diabetes Melitus pada Penderita Diabetes Melitus Tipe 2 di Desa Ngadiwarno Sukorejo Kendal (Bachelor's thesis, UIN Syarif Hidayatullah Jakarta: Fakultas Kedokteran dan IImu Kesehatan, 2017).

Perkumpulan Endokrinologi Indonesia. (2011). Konsensus Pengendalian dan Pengetahuan Diabetes Mellitus Tipe 2 di Indonesia 2011. Jakarta: Perkeni.

Rahmaningsih, B. Y., Hidayat, N. S. P., \& Novita, I. N. M. (2016). Hubungan antara nilai ankle brachial index dengan kejadian diabetic foot ulcer pada penderita diabetes melitus tipe $2 \mathrm{di}$ RSUD Dr. Moewardi Surakarta (Doctoral dissertation, Universitas Muhammadiyah Surakarta).
Rantung, J., Yetti, K., \& Herawati, T. (2015). Hubungan self-care dengan kualitas hidup pasien diabetes mellitus (DM) di persatuan diabetes indonesia (Persadia) Cabang Cimahi. Jurnal Skolastik Keperawatan, 1(01).

Rosikhoh, N. I. (2016). Gambaran penderita gangren dan identifikasi faktor pemicu kejadian gangren pada penderita diabetes mellitus. Skripsi.

Sari, N., \& Hisyam, B. (2014). Hubungan Antara Diabetes Melitus Tipe li dengan Kejadian Gagal Ginjal Kronik di Rumah Sakit PKU Muhammadiyah Yogyakarta Periode Januari 2011-Oktober 2012. Jurnal Kedokteran dan Kesehatan Indonesia, 6(1), 12-19.

Senussi, M., Lincoln, N., \& Jeffcoate, W. (2011). Psychometric properties of the Nottingham Assessment of Functional Footcare (NAFF). International Journal of Therapy and Rehabilitation, 18(6), 330-334.

Utami, S. P. (2017). Upaya Senam Kaki untuk Mencegah Resiko Komplikasi Pada Tn. S dengan Diabetes Mellitus (Doctoral dissertation, Universitas Muhammadiyah Surakarta).

Wantiyah, W., \& Susanto, T. (2014). Pengaruh Diabetes Self Management Education (DSME) terhadap Resiko Terjadinya Ulkus Diabetik pada Pasien Rawat Jalan dengan Diabetes Mellitus (DM) Tipe 2 di RSD dr. Soebandi Jember (The Influence of Diabetes Self Management Education (DSME) to The Risk. Pustaka Kesehatan, 2(1), 119-124.

Waspadji, S., \& Bachtiar, A. (2006). Predictor of mortality and rehospitalization of acute decompensated heart failure at six months follow up. Crit Care \& Shock, 9(3), 61-7.

Widayati, N. (2015). Hambatan dan Strategi Koping dalam Manajemen Perawatan Diri Penderita Diabetes Melitus Tipe 2 di Wilayah Kerja Puskesmas Jember Kidul Kabupaten Jember.

\footnotetext{
Ummu Habibah' Akademi Keperawatan Bhakti Husada Cikarang, Banten. Email: hb_ummu@yahoo.com Busjra M. Nur ${ }^{2}$ Fakultas llmu Keperawatan, Universitas Muhammadiyah Jakarta Eka Yudha Chrisanto ${ }^{3}$ Akademi Keperawatan Malahayati Bandar Lampung. Email: yudhachrisanto88@gmail.com
} 


\section{EDUKASI PENGELOLAAN KAKI DIABETIK TERHADAP KEMAMPUAN KLIEN MENGIDENTIFIKASI RISIKO ULKUS DIABETIK}

Windasari, N. N. (2015). Pendidikan Kesehatan dalam Meningkatkan Kepatuhan Merawat Kaki pada Pasien Diabetes Mellitus Tipe II. IJNP (Indonesian Journal of Nursing Practices), 2(1), 79-90.

Yunir, E., Waspadji, S., \& Rahajeng, E. (2009). The pre-diabetic epidemiological study in Depok, West Java. Acta Med Indones, 41(4), 181-5.
Yunus, B. (2015). Faktor-faktor yang Mempengaruhi Lama Penyembuhan Luka pada Pasien ULKUS Diabetikum di Rumah Perawatan ETN Centre Makassar (Doctoral dissertation, UIN Alauddin Makassar).

Ummu Habibah' Akademi Keperawatan Bhakti Husada Cikarang, Banten. Email: hb_ummu@yahoo.com Busjra M. Nur ${ }^{2}$ Fakultas llmu Keperawatan, Universitas Muhammadiyah jakarta

Eka Yudha Chrisanto ${ }^{3}$ Akademi Keperawatan Malahayati Bandar Lampung.

Email: yudhachrisanto88@gmail.com 